Molecules 2003, 8, 901-909

molecules

ISSN 1420-3049

http://www.mdpi.org

\title{
New Bioactive Azaartemisinin Derivatives
}

\section{Mai M. Al-Oqail, Ahmed M. Galal ${ }^{1}$, Mohamed S. Ahmad, Ahlam M. Al-Fishawi ${ }^{1}$ and Farouk S. El-Feraly*}

Department of Pharmacognosy, College of Pharmacy, King Saud University, P.O. Box 2457, Riyadh 11451, Saudi Arabia.

${ }^{1}$ Current address:Department of Pharmacognosy, Faculty of Pharmacy, Cairo University, Kasr El-Eini, Cairo 11562, Egypt.

*Author to whom correspondence should be addressed; e-mail: fferaly@yahoo.com

Received: 19 February 2003; in revised form 5 October 2003 / Accepted: 24 November 2003 /

Published: 31 December 2003

\begin{abstract}
Reaction of artemisinin (1) with ethanolamine, followed by acid treatment produced the lactam $(4 S, 8 S, 9 S, 13 S, 1 R, 5 R, 12 R)$-11-aza-11-(2-hydroxyethyl)-1,5,9trimethyl-14,15-dioxatetracyclo $[10.2 .1 .0<4,13>.0<8,13>$ pentadecan-10-one (4) and the diol (1S,2S,6S,7S,5R,8R)-4-aza-5,6-dihydroxy-4-(2-hydroxyethyl)-2,8-dimethyl-7-(3-oxobutyl)bicyclo[4.4.0]decan-3-one (7). When ethylenediamine was used instead of the ethanolamine, the dimeric lactam $(1 S, 4 S, 8 S, 9 S, 13 S, 5 R, 12 R)-11-[2-((1 S, 4 S, 8 S, 9 S, 13 S, 5 R$, 12R)-11-aza-1,5,9-trimethyl-14,15-dioxa-10-oxotetracyclo[10.2.1.0<4,13>.0<8,13>] pentadec-11-yl)ethyl]-11-aza-1,5,9-tri-methyl-14,15-dioxatetracyclo-[10.2.1.0<4,13>.0<8,13>]pentadecan-10-one (8) was obtained. All compounds are new azaartemisinin derivatives lacking the peroxide functionality. These compounds were evaluated for antimalarial and cytotoxic activities. Only the dimer $\mathbf{8}$ was found to possess antimalarial activity, while only the diol 7 exhibited cytotoxic activity against human breast ductal carcinoma.
\end{abstract}

Keywords: Artemisinin, azaartemisinin derivatives, bioactivity, NMR. 


\section{Introduction}

Artemisinin (formerly referred to variously as artemisinine or arteannuin and as qinghaosu in Chinese) is the main antimalarial principle isolated from the Chinese weed Artemisia annua L. Its structure was correctly defined in 1972 [1] as a sesquiterpene lactone with a rare endoperoxide bridge. The structure elucidation was supported by spectral data and also by X-ray crystallography. Artemisinin is now commercially available in China and Vietnam as an antimalarial drug efficacious against conventional drug-resistant strains of Plasmodium falciparum, a common malarial parasite. A semisynthetic drug based on artemisinin, namely, artemether (2), has been registered in France under the trade name of Paluther ${ }^{\circledR}$.

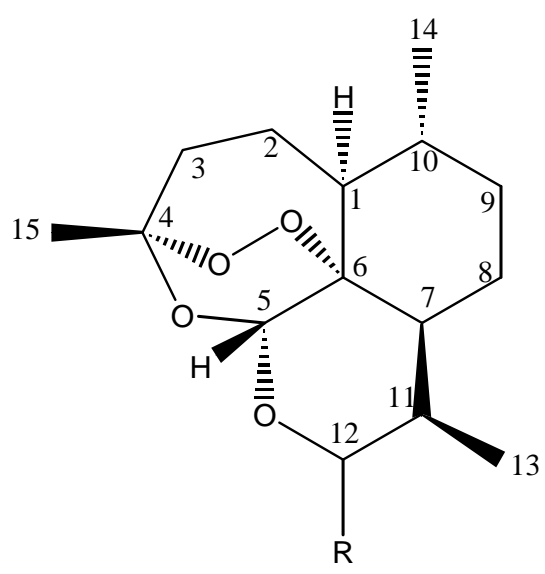

$\mathrm{R}:=\mathrm{O} \quad \mathbf{1}$

$\mathrm{R}: \sim \mathrm{OH} \quad$ Dihydroartemsinin (3)

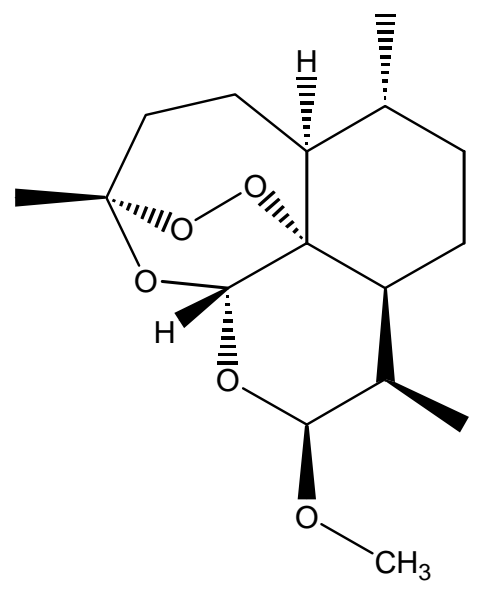

Artemether (2)

The majority of artemisinin derivatives prepared to-date have been mostly esters, ethers, or urethane derivatives of the hydroxyl group of dihydroartemisinin (3). The greater stability of lactams to acidic conditions, such as those present in the stomach, should reduce the destruction of the drug that occurs there and might, therefore, lead to an increase in the drug's bioavailability. Moreover, incorporating a lipophilic or hydrophilic substituent on the lactam nitrogen should provide a means to control the drug's solubility properties. Thus, it was attractive to try to make aza-derivatives of artemisinin, which was accomplished by a two-step reaction sequence between $\mathbf{1}$ and ammonia or amines, followed by treatment with a mixture of aqueous sulfuric acid/silica gel to yield $N$-substituted 11-azaartemisinins (CA numbering) in similar or greater yields [2].

In vitro and in vivo test data for a number of novel $N$-substituted 11 -azaartemisinins, against drugresistant strains of Plasmodium falciparum, showed that they possessed antimalarial activity equal to or greater than that of compound 1 itself. The most active derivative was $N$-(2 -acetaldehydo)-11azaartemisinin, as it was 26 times more active in vitro, and 4 times more active in vivo, than 1 [2]. Also recently, azaartemisinin analogues displayed herbicidal activity [3] besides the known antimalarial activity. 
This manuscript deals with the preparation, identification and antimalarial activity of new nitrogenous artemisinin derivatives (azaartemisinins) obtained by reacting it with ethanolamine and ethylenediamine. It was hoped that the presence of additional polar groups would contribute to the water solubility of the products without diminishing their activity.

\section{Results and Discussion}

The preparation of nitrogenous derivatives of $\mathbf{1}$ was particularly attractive, as it represents an active antimalarial agent devoid of the nitrogen atoms which are encountered in all other natural and synthetic antimalarial agents, such as quinine, chloroquine and mefloquine. It was assumed that the addition of nitrogen to the molecule of $\mathbf{1}$ might modify in a favorable way the antimalarial activity of this compound. Furthermore, the preparation of nitrogenous dimeric artemisinin derivatives was also expected to lead to other interesting biological activities, and perhaps also better physical properties. This notion was based on the fact that it has been previously reported [2] that lactam analogs of 1 showed better acid stability and hence more bioavailability, as well as more potency against Plasmodium falciparum.

Consequently, in this project, it was deemed interesting to treat compound 1 with 4-aminoquinoline and 8-aminoquinoline in anticipation of obtaining lactams that would combine the unique antimalarial properties of artemisinin with those expected from the quinoline nucleus, found in numerous conventional antimalarial agents, notably chloroquine and primaquine. Unfortunately, the reaction of either of these two compounds with compound 1 did not proceed at all, even by refluxing in toluene. It appears that the primary amino groups of these compounds were not sufficiently basic to react with the lactone group of $\mathbf{1}$. It is worth noting that the reaction of 1 with 4-aminopyridine did not proceed either, apparently for the same reason.

Attention was then focused on reacting compound $\mathbf{1}$ with a hydroxylated amine and the simplest one that could be considered was ethanolamine. It was thought that the presence of the hydroxyl group might lend itself for further derivatization towards a more water soluble product. The reaction of $\mathbf{1}$ with ethanolamine proceeded smoothly over a short period of time (see Experimental) to give a polar adduct. Acid treatment followed by chromatography over silica gel gave the lactam $(4 S, 8 S, 9 S, 13 S, 1 R, 5 R, 12 R)$-11-aza-11-(2-hydroxyethyl)-1,5,9-trimethyl-14,15-dioxatetracyclo [10.2.1.0 $<4,13>.0<8,13>$ ]pentadecan-10-one (4), which lacked the peroxide function. The identification of 4 was based on its spectral data (see Experimental), with the HRMS suggesting the molecular formula $\mathrm{C}_{17} \mathrm{H}_{27} \mathrm{NO}_{4}$. Furthermore, the ${ }^{13} \mathrm{C}-\mathrm{NMR}$ spectrum showed the C-4 and the C-6 signals at $\delta 107.3$ and 82.5, respectively, which is characteristic of deoxyartemisinin derivatives [2]. In artemisinin derivatives, on the other hand, these two carbon signals resonate at higher field positions by at least 3 ppm [2]. Also, the presence of a primary alcohol group was substantiated by its facile acetylation to form 5. The formation of $\mathbf{4}$, instead of the expected peroxide derivative can be attributed to the reduction of the peroxide group by the strongly basic amine (ethanolamine) to give the corresponding $N$-oxide [2]. 
Attempts to produce the peroxy analog of $\mathbf{4}$ by reducing the amount of the amine were unsuccessful. It is intriguing to note that compound $\mathbf{4}$ has the same ethanolamine moiety found in anandamide (6)[4], the cannabinoids neurotransmitter responsible for their effects on short term memory and blood pressure. It would be of interest to find out if $\mathbf{4}$ could mimic any of these effects.

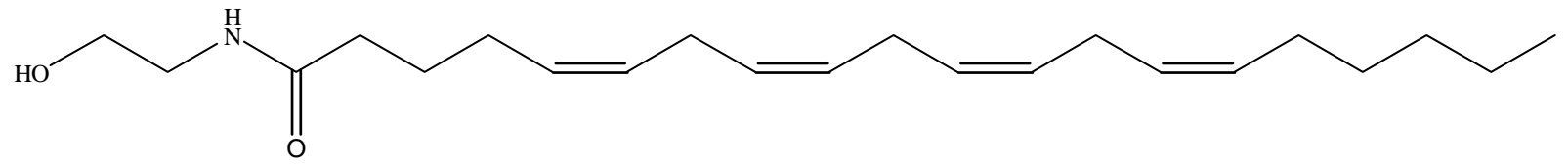

Anandamide (6)

It should be noted that in the reaction leading to $\mathbf{4}$, working up the reaction mixture without chromatography did not result in the production of $\mathbf{4}$, rather the more polar diol $(1 S, 2 S, 6 S, 7 S, 5 R, 8 R)-4$ aza-5,6-dihydroxy-4-(2-hydroxyethyl)-2,8-dimethyl-7-(3-oxobutyl)bicyclo[4.4.0]decan-3-one (7) was obtained. The structure elucidation of 7 was based on its molecular formula, $\mathrm{C}_{17} \mathrm{H}_{29} \mathrm{NO}_{5}$, and spectral data (see Experimental), which exhibited a ketone function, a lactam group and two oxygenated carbon signals at $\delta 81.3$ (methine) and 72.5 (quaternary) due to the diol at C-5 and C-6, respectively. The formation of 7 can be rationalized on the basis of related studies [2,5] as shown in the steps of Scheme 1. It should be pointed out that a peroxy analog of 7 was postulated as an intermediate in the reaction of other amines with artemisinin to yield peroxylactams. However, it has never before been isolated or characterized [2].

Scheme 1.
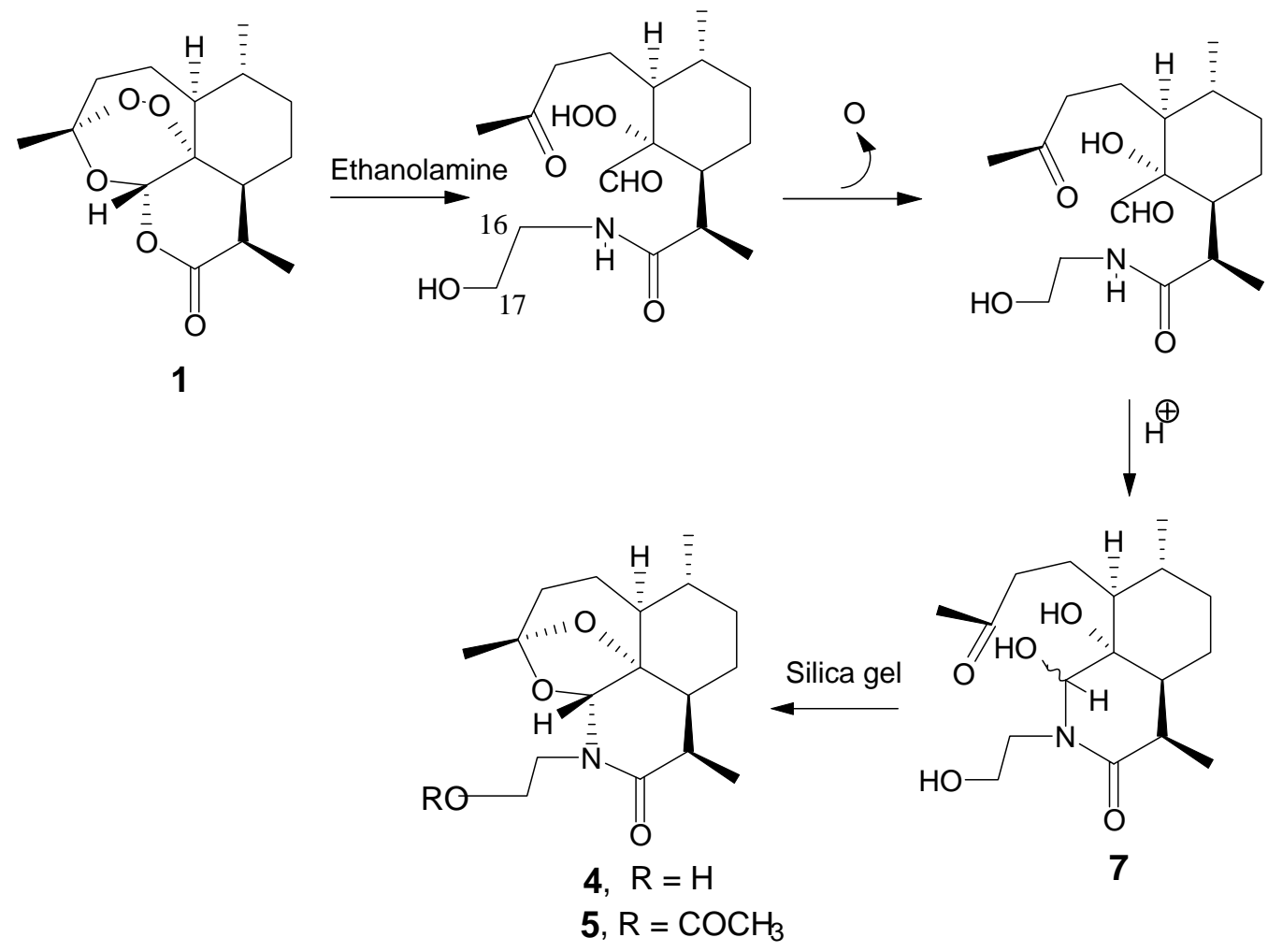
Compounds 4, and 7 were evaluated for antimalarial and cytotoxic (ability to inhibit the proliferation of cancerous cells at an $\mathrm{IC}_{50}$ of $<10 \mu \mathrm{g} / \mathrm{mL}$ ) activities. Compound 4 was devoid of antimalarial or cytotoxic activities. The results of antimalarial testing are shown in Table 1. Only the diol 7 was found to be cytoxic to human breast ductal carcinoma with an $\mathrm{IC}_{50}$ of $2.7 \mu \mathrm{g}(8.2 \mathrm{nM}) / \mathrm{mL}$.

The reaction between ethanolamine and artemisinin to produce 4 made it of interest to try the same reaction with a diamino compound like ethylenediamine. It was expected that such a reaction would lead to the formation of a dimer consisting of two artemisinin units connected by an ethylene bridge. Thus, 1 was stirred in methanolic solution with ethylenediamine to form an adduct in an almost quantitative yield and within a short period of time (see Experimental). Acidification of the reaction mixture produced a number of products one of which gave a positive Dragendorff's test. This product was separated by column chromatography to yield the dimer $(4 S, 8 S, 9 S, 13 S, 1 R, 5 R, 12 R)-11$-[2$((4 S, 8 S, 9 S, 13 S, 1 R, 5 R, 12 R)$-11-aza-1,5,9-trimethyl-14,15-dioxa-10-oxotetracyclo $\quad[10.2 .1 .0<4,13>.0$ $<8,13>$ ]pentadec-11-yl)ethyl]-11-aza-1,5,9-trimethyl-14,15-dioxatetracyclo $[10.2 .1 .0<4,13>.0<8,13>]$ pentadecan-10-one $(\mathbf{8})$.

The dimeric nature of compound $\mathbf{8}$ was based on its molecular formula $\mathrm{C}_{32} \mathrm{H}_{48} \mathrm{~N}_{2} \mathrm{O}_{6}$ as suggested by its HRMS (see Experimental). The ${ }^{13} \mathrm{C}-\mathrm{NMR}$ spectra clearly indicated that the dimer was symmetrical as it exhibited only 16 carbon signals. The symmetrical ethylene bridge of $\mathbf{8}$ showed geminal coupling, since it resonated as a pair of doublets at $\delta 4.95$ and $3.39(\mathrm{~J}=9.8 \mathrm{~Hz})$. Also, the ${ }^{13} \mathrm{C}$-NMR spectra indicated that $\mathbf{8}$ is not a peroxy derivative, rather it has an oxide bridge between C-4 and C-6. This was based on the relatively downfield positions of these carbons at $\delta 106.9$ and 82.1, respectively, as discussed earlier [2]. This notion was further confirmed by its molecular formula.

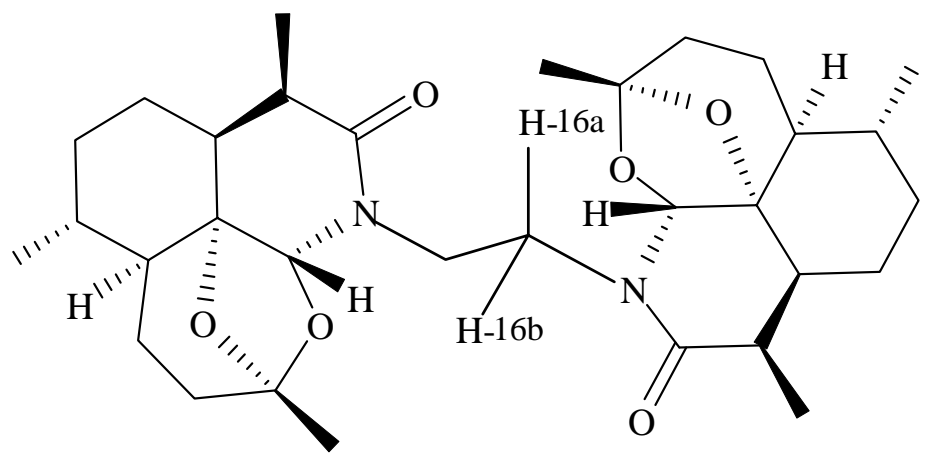

It is very interesting to note that although the dimer $\mathbf{8}$ does not have a peroxide group, it showed a high degree of activity as an antimalarial agent. Its $\mathrm{IC}_{50}$ values against $P$. falciparum (D-6 and W-2 Clones) were close to those of $\mathbf{1}$, as shown in Table 1 . Clearly this is due to its unique structure, and perhaps also due to the presence of the two nitrogen atoms, which are found in all conventional 
antimalarial agents. Attempts are now in progress to prepare additional related dimers in which the peroxide group is preserved.

Table 1. Antimalarial activity of compounds 1,4, 7 and 8

\begin{tabular}{|c|c|c|}
\hline \multirow{2}{*}{ Compound } & $\begin{array}{c}\text { P.falciparum (D6 Clone) } \\
\mathrm{IC}_{50}\end{array}$ & $\begin{array}{c}\text { P.falciparum (W2 Clone) } \\
\mathrm{IC}_{50}\end{array}$ \\
\hline $\mathbf{1}$ & $6-10 \mathrm{ng} / \mathrm{mL}(21.3-35.5 \mathrm{nM})$ & $6-10 \mathrm{ng} / \mathrm{mL}(21.3-35.5 \mathrm{nM})$ \\
$\mathbf{4}$ & $>400 \mathrm{nM}$ & $>400 \mathrm{nM}$ \\
$\mathbf{7}$ & $>400 \mathrm{nM}$ & $>400 \mathrm{nM}$ \\
$\mathbf{8}$ & $12.0 \mathrm{ng} / \mathrm{mL}(21.6 \mathrm{nM})$ & $8.7 \mathrm{ng} / \mathrm{mL}(15.6 \mathrm{nM})$ \\
\hline
\end{tabular}

\section{Acknowledgements}

Thanks for technical assistance with the biological evaluations are extended to Mrs. Sharon Sanders, Mr. Charlie Dawson, Mr. John Trott and Mrs. Miranda Logan of the National Center for Natural Products Research, Research Institute of Pharmaceutical Sciences, School of Pharmacy, University of Mississippi, University, Mississippi 38677, USA.

\section{Experimental}

\section{General}

Artemisinin was isolated from locally grown Artemisia annua by extraction with $n$-hexane, using continuous hot extraction, followed by solvent partitioning and chromatography as previously described [6]. Thin layer chromatography (TLC) was performed using pre-coated silica gel 60 F-254 glass plates (Merck), $5 \times 10 \mathrm{~cm}, 0.25 \mathrm{~mm}$ thick and activated by heating at $110^{\circ} \mathrm{C}$ for one hour. The solvent system used was $4 \%$ ethyl acetate in dichloromethane, unless otherwise specified. Spots were visualized using anisaldehyde-sulfuric acid spray reagent, which was prepared as previously reported [7]. The reagent was sprayed on TLC plates, which were then heated with a hot air gun until color development was complete. Flash column chromatography was performed using silica gel 60, particle size 0.04-0.063 mm, 230-400 mesh, ASTM (E. Merck, Germany) and activated by heating at $110^{\circ} \mathrm{C}$ for one hour prior to use. Melting points were determined on a Mettler FP 80 Central Processor supplied with a Mettler FP 81 MBC Cell apparatus, and were uncorrected. Specific rotations, $[\alpha]_{D}^{22}$, were measured as solutions in chloroform, unless otherwise specified, on a Perkin-Elmer 242 MC polarimeter, using a one-decimeter tube. Infrared spectra were obtained in potassium bromide pellets using a Perkin-Elmer Model 1000 or 1600 spectrophotometers. ${ }^{1} \mathrm{H}$ - and ${ }^{13} \mathrm{C}-\mathrm{NMR}$ spectra were recorded on an AMX Bruker NMR spectrometer operating at 300, 400 or $500 \mathrm{MHz}$ for ${ }^{1} \mathrm{H}-$, and 75 , 
100 and $125 \mathrm{MHz}$, respectively, for ${ }^{13} \mathrm{C}-\mathrm{NMR}$. The chemical shift values were reported in $\delta$ (ppm) units using tetramethylsilane (TMS) as an internal standard, and the coupling constants (J) are in Hz. Abbreviations for NMR signals are as follows: $\mathrm{s}=$ singlet, $\mathrm{d}=$ doublet, $\mathrm{m}=$ multiplet. Standard pulse sequences were used for generating DEPT, COSY, HMQC and HMBC spectra, which aided the carbon and proton assignments. High resolution mass spectra (HRMS) were obtained using a Bruker Bioapex FTMS spectrometer with electrospray ionization. The IUPAC nomenclature of compounds 4 , 7 and 8 was generated using the program Chemistry 4-D Draw Office, version 6.01a, purchased from ChemInnovation Software, Inc.

\section{Preparation of the $\mathrm{N}-$ Substituted derivatives $\mathbf{4}$ and $\mathbf{7}$ from $\mathbf{1}$.}

To a solution of ethanolamine $(0.5 \mathrm{~mL})$ in methanol $(5 \mathrm{~mL})$ at room temperature was added 1 (500 $\mathrm{mg}$ ). The solution was stirred for 3 hours then concentrated under reduced pressure to give a light yellow solid residue. The residue was dissolved in $\mathrm{CH}_{2} \mathrm{Cl}_{2}$ (70 mL) then 2,6-di-tert-butyl-4methylphenol (BHT) (47 mg), 15\% $\mathrm{H}_{2} \mathrm{SO}_{4}$ (15 drops), and silica gel (4 g) were added in succession. After stirring overnight at room temperature, the reaction mixture was filtered and the silica gel washed with $\mathrm{CH}_{2} \mathrm{Cl}_{2}$. The combined organic solution and washes were concentrated under reduced pressure. Flash column chromatography of the residue gel with $\mathrm{CHCl}_{3}$ as eluent gave $\mathbf{4}$ as a crystalline solid (50 mg): mp: $92-93^{\circ} \mathrm{C}$; $\mathrm{R}_{\mathrm{f}} 0.19$ [ethyl acetate: $\mathrm{CH}_{2} \mathrm{Cl}_{2} 2: 8$ ]; $[\alpha]_{\mathrm{D}}^{22}+321^{\circ}\left(\mathrm{c}=0.10, \mathrm{CHCl}_{3}\right)$; IR: $\nu_{\max }\left(\mathrm{cm}^{-1}\right): 1619(\mathrm{C}=\mathrm{O})$ and $3271(\mathrm{OH}) ;{ }^{1} \mathrm{H}-\mathrm{NMR}\left(\mathrm{C}_{6} \mathrm{D}_{6}\right): \delta 1.03(\mathrm{~m}, 1 \mathrm{H}, \mathrm{H}-1), 1.58(\mathrm{~m}, 2 \mathrm{H}, \mathrm{H}-2)$, 1.50 (m, 2H, H-3), 4.98 (s, 1H, H-5), 1.79 (m, 1H, H-7), 0.82 (m, 2H, H-8), 1.39 (m, 2H, H-9), 1.50 (m, 1H, H-10), 3.24 (m, 1H, H-11), 1.26 (d, J=7.33 Hz, 3H, H-13), 0.72 (d, J=6.1 Hz, 3H, H-14), 1.41 (s, 3H, H-15), 3.53 (m, 1H, H-16a or H-16b), 3.96 (m, 1H, H-16b or H-16a), 3.94 (m, 2H, H-17a, H17b); ${ }^{13} \mathrm{C}-\mathrm{NMR}\left(\mathrm{CDCl}_{3}\right): \delta 46.0(\mathrm{C}-1), 22.4(\mathrm{C}-2), 35.0(\mathrm{C}-3), 107.4(\mathrm{C}-4), 87.6(\mathrm{C}-5), 82.5(\mathrm{C}-6)$, 43.6 (C-7), 23.1 (C-8), 33.9 (C-9), 35.2 (C-10), 33.8 (C-11), 172.3 (C-12), 13.1 (C-13), 18.7 (C-14), 24.5 (C-15), 49.6 (C-16) , 62.3 (C-17) ; HRMS: Calculated for $\mathrm{M}^{+}+1, \mathrm{C}_{17} \mathrm{H}_{28} \mathrm{NO}_{4}, 310.2007$ found: 310.2019 .

When the reaction was repeated as described for the formation of $\mathbf{4}$, but instead of flash column chromatography, the residue was crystallized from $n$-hexane/ether, $60 \mathrm{mg}$ of 7 were obtained as colorless prisms, mp: $125-125.1^{\circ} \mathrm{C} ; \mathrm{R}_{\mathrm{f}} 0.08$ [ethyl acetate- $\mathrm{CH}_{2} \mathrm{Cl}_{2} 4: 6$ ]; IR: $v_{\max }\left(\mathrm{cm}^{-1}\right): 3470(\mathrm{OH})$ and $1681(\mathrm{C}=\mathrm{O}) ;{ }^{1} \mathrm{H}-\mathrm{NMR}\left(\mathrm{CDCl}_{3}\right): \delta 0.96(\mathrm{~m}, 1 \mathrm{H}, \mathrm{H}-1), 1.41(\mathrm{~m}, 2 \mathrm{H}, \mathrm{H}-2), 2.51(\mathrm{~m}, 2 \mathrm{H}, \mathrm{H}-3), 4.76$ (s, 1H, H-5), 1.55 (m, 1H, H-7), 1.51 (m, 2H, H-8), 1.58 (m, 1H, H-9), 1.55 (m, 1H, H-10), 2.95 (m,1H, H-11), 0.92 (d, J=7.2 Hz, 3H, H-13) , 0.88 (d, J=6.4 Hz, 3H, H-14) , 2.04 (s, 3H, H-15), 3.24 (m, 1H, H-16a or H-16b) 3.42 (m, 1H, H-16b or H-16a), 3.44 (m, 2H, H-17a, H-17b); ${ }^{13} \mathrm{C}-\mathrm{NMR}$ $\left(\mathrm{CDCl}_{3}\right): \delta 54.3(\mathrm{C}-1), 21.8(\mathrm{C}-2), 44.8(\mathrm{C}-3), 210(\mathrm{C}-4), 81.3(\mathrm{C}-5), 72.5(\mathrm{C}-6), 49.4(\mathrm{C}-7), 22.7(\mathrm{C}-$ 8), 35.1 (C-9), 35.5 (C-10), 33.8 (C-11), 170 (C-12), 13.8 (C-13), 21.3 (C-14), 30.5 (C-15), 46.2 (C16), 59.6 (C-17); HRMS: Calculated for $\mathrm{M}^{+}+1, \mathrm{C}_{17} \mathrm{H}_{30} \mathrm{NO}_{5}, 328.2124$, found: 328.2123 . 
Acetylation of compound 4 to form 5 .

To a solution of compound $4(25 \mathrm{mg})$ in pyridine $(0.5 \mathrm{~mL})$ at room temperature was added acetic anhydride $(1 \mathrm{~mL})$ and the solution was left overnight at room temperature. The resulting mixture was extracted with $\mathrm{CHCl}_{3}(20 \mathrm{~mL})$ then washed twice with $5 \% \mathrm{NaHCO}_{3}(10 \mathrm{~mL}), 5 \% \mathrm{H}_{2} \mathrm{SO}_{4}(10 \mathrm{~mL}), \mathrm{H}_{2} \mathrm{O}$ $(10 \mathrm{~mL}), 5 \% \mathrm{NaHCO}_{3}$ and finally with $\mathrm{H}_{2} \mathrm{O}$. The organic portions were collected, dried over anhydrous sodium sulfate and concentrated to give $5(30 \mathrm{mg})$ as an oil, $\mathrm{R}_{\mathrm{f}} 0.64$ [ethyl acetate- $\mathrm{CH}_{2} \mathrm{Cl}_{2}$ 2:8]; $[\alpha]_{\mathrm{D}}^{22}+301^{\mathrm{o}}\left(c=0.10, \mathrm{CHCl}_{3}\right)$; IR: $v_{\max }\left(\mathrm{cm}^{-1}\right): 1737\left(\mathrm{CH}_{3} \underline{\mathrm{CO}}\right), 1649$ (lactam $\left.\mathrm{C}=\mathrm{O}\right) ;{ }^{1} \mathrm{H}-\mathrm{NMR}$ $\left(\mathrm{CDCl}_{3}\right): \delta 1.19(\mathrm{~m}, 1 \mathrm{H}, \mathrm{H}-1), 1.68(\mathrm{~m}, 2 \mathrm{H}, \mathrm{H}-2), 5.06$ (s,1H, H-5), $1.86(\mathrm{~m}, 1 \mathrm{H}, \mathrm{H}-7), 0.64(\mathrm{~m}, 2 \mathrm{H}, \mathrm{H}-$ 8), 1.65 (m, 1H, H-10), 2.97 (m, 1H, H-11), 1.06 (d, J = 7.4 Hz, 3H, H-13), 0.86 (d, J = 5.8 Hz, 3H, H14), 1.36 (s, 3H, H-15), 3.43 (unresolved,1H, H-16a or H-16b), 3.78 (unresolved, 1H, H-16b or H16a), 4.19 (m, 2H, H-17a, H-17b), 1.96 (s, 3H, H-19), H-3 and H-9 were not assigned due to overlapping signals and for lack of sufficient data; ${ }^{13} \mathrm{C}-\mathrm{NMR}\left(\mathrm{CDCl}_{3}\right)$ : $43.3(\mathrm{C}-1), 20.9(\mathrm{C}-2), 34.6(\mathrm{C}$ 3), 107.3 (C-4), 86.6 (C-5), 82.5 (C-6), 43.0 (C-7), 22.7 (C-8), 33.5 (C-9), 35.4 (C-10), 33.1 (C-11), 170 (C-12), 12.4 (C-13), 18.5 (C-14), 24.2 (C-15), 45.6 (C-16), 62.3 (C-17), 171.8 (C-18), 22.1 (C-19); HRMS: Calculated for $\mathrm{M}^{+}+1, \mathrm{C}_{19} \mathrm{H}_{30} \mathrm{NO}_{5}, 352.21239$, found: 352.2122.

\section{Preparation of the nitrogenous dimer $\mathbf{8}$.}

To a stirred solution of $1(500 \mathrm{mg})$ in methanol $(5 \mathrm{~mL})$, was added ethylenediamine $(0.3 \mathrm{~mL})$, and the reaction was monitored by TLC. After the disappearance of the artemisinin (about 3 hours), the solvent was evaporated to leave a light yellow oily residue. The residue was redissolved in $\mathrm{CH}_{2} \mathrm{Cl}_{2}$ $(70 \mathrm{~mL})$ then 2,6-di-tert-butyl-4-methylphenol (BHT)(47 mg), 15\% $\mathrm{H}_{2} \mathrm{SO}_{4}$ (15 drops) and silica gel (4 g) were added in succession. After stirring overnight at room temperature, the reaction mixture was filtered and the silica gel washed with $\mathrm{CH}_{2} \mathrm{Cl}_{2}$. The combined organic solution and washes were concentrated under reduced pressure. Flash column chromatography of the residue using $\mathrm{CHCl}_{3}$ as eluent gave 8 as a slightly tan solid (20 mg); mp: 251-251.2 ${ }^{\circ} \mathrm{C} ; \mathrm{R}_{\mathrm{f}} 0.87$ [ethyl acetate- $\mathrm{CH}_{2} \mathrm{Cl}_{2} 4: 6$ ]; $[\alpha]_{\mathrm{D}}^{22}-67^{\circ}\left(c=0.10, \mathrm{CHCl}_{3}\right)$; IR: $v_{\max }\left(\mathrm{cm}^{-1}\right): 1619(\mathrm{C}=\mathrm{O}) ;{ }^{1} \mathrm{H}-\mathrm{NMR}\left(\mathrm{C}_{6} \mathrm{D}_{6}\right): \delta 1.15(\mathrm{~m}, 1 \mathrm{H}, \mathrm{H}-1), 1.07$ (m, 2H, H-2), 1.51 (m, 2H, H-3), 5.70 ( $s, 1 \mathrm{H}, \mathrm{H}-5), 1.89$ (m, 1H, H-7), 1.60 (m, 2H, H-8), 1.14 (m, 2H, H-9), 1.75 (m, 1H, H-10), 3.27 (m, 1H, H-11), 1.23 (d, J=7.2 Hz, 3H, Me-13), 0.86 (d, J=5.6 Hz, 3H, Me-14); 1.43 (s, 3H, Me-15), 4.95 (d, J=9.8 Hz, 1H, H-16a or H-16b), 3.39 (d, J=9.8 Hz, 1H, H-16b or H-16a); ${ }^{13} \mathrm{C}-\mathrm{NMR}\left(\mathrm{CDCl}_{3}\right): \delta 46.1$ (C-1), 21.9 (C-2), 34.6 (C-3), $\left.106.9 \mathrm{C}-4\right), 83.6$ (C-5), 82.1 (C-6), 42.7 (C-7), 22.6 (C-8), 33.8 (C-9), 33.7 (C-10), 33.2 (C-11), 170.9 (C-12), 12.4 (C-13), 18.5 (C-14), 24.1 (C-15), 37.8 (C-16); HRMS: Calculated for $\mathrm{M}^{+}+1, \mathrm{C}_{32} \mathrm{H}_{49} \mathrm{~N}_{2} \mathrm{O}_{6}, 557.3591$, found: 557.3581 .

\section{Bioactivity testing}

Antimalarial and cytotoxic activity were tested according to procedures reported elsewhere $[8,9$, respectively]. 


\section{References}

1. Klayman, D.L. Qinghaosu (Artemisinin): An antimalarial drug from China. Science 1985, 288, 1049.

2. Torok, D.S.; Ziffer, H.; Meshnick, S.R.; Pan X.Q.; Ager, A. Synthesis and antimalarial activities of $N$-Substituted 11-azaartemisinins. J. Med. Chem. 1995, 38, 5045.

3. Dayan, F.E.; Hernandez, A.; Allen, S.N.; Moraes, R.M.; Vroman, J.A.; Avery, M.A.; Duke, S.O. Comparative phytotoxicity of artemisinin and several sesquiterpene analogues. Phytochemistry 1999, $50,607$.

4. Khanolkar, A.D.; Makriyannis, A. Structure-activity relationships of anandamide, an endogenous cannabinoid ligand. Life Sci. 1999, 65, 607.

5. Mei-Yi, Z.; Lan-Na, L.; Chu-Peng, C.; Guang-Yi, L.; Xian-Tian, L.; Chen, M.; Clardy, J. Chemical tranformations of qinghaosu, a peroxidic antimalarial . Tetrahedron 1983, 39, 2941.

6. ElSohly, H.N.; Croom, E.M. JR; El-Feraly; F.S.; El-Sherei; M.M. A large-scale extraction technique of artemisinin from Artemisia annua. J. Nat . Prod. 1990, 53, 1560.

7. El-Feraly, F.S.; Hufford, C.D.Synthesis and C-13 NMR assignments of xenognosin. J. Org. Chem. 1982, 47, 1527.

8. El-Sayed, K.A.; Dunbar, D.C.; Goins, D.K.; Cordoya, C.R.; Perry, T.L.; Weeson, K.J.; Sanders, S.C.; Janus, S.A.; Humman, M. The marine environment: A resource for prototype antimalarial agents. J. Nat. Toxins J. Nat. Toxins 1996, 5, 261.

9. Muhammad, I., Dunbar, D., Takamatsu, S., Walker, L. A., Clark, A. M. Antimalarial, cytotoxic, and antifungal alkaloids from Duguetia hadrantha. J. Nat . Prod. 2001, 64, 559.

Sample Availability: Available from the authors

(C) 2003 by MDPI (http://www.mdpi.org). Reproduction is permitted for noncommercial purposes. 